\title{
La vivienda nueva en la ciudad de Chihuahua: oferta y demanda
}

\section{New housing stock in Chihuahua City, Mexico: supply and demand}

\author{
María de Lourdes Romo-Aguilar \\ Gustavo Córdova-Bojórquez \\ CÉsar Fuentes-Flores \\ Alejandro Brugués-Rodríguez*
}

\begin{abstract}
This article analyzes the role of State-sponsored programs and real estate market in shaping housing availability in the city of Chihuahua, Mexico, from 2000 to 2005. Not only does this analysis deal with quantitative terms, but also qualitative aspects such as: sufficient space; public health provisions that include potable water supply, sewage and waste management services; and urban infrastructure. This paper is divided into seven sections: 1) conceptual-theoretical notes about housing; 2) institutional development in relation to housing in Mexico; 3) a review of urban growth and development of the city of Chihuahua; 4) housing characteristics in the city and new housing development; 5) new housing supply for this particular case; 6) housing demand; and 7) conclusion.
\end{abstract}

Keywords: housing, urban growth, Chibuahua city, supply, demand.

\begin{abstract}
Resumen
El objetivo del presente artículo es analizar el papel del gobierno y del mercado inmobiliario en relación con la disponibilidad de vivienda nueva en la ciudad de Chihuahua en el periodo 2000-2005, no sólo en términos cuantitativos sino también en calidad en cuanto a que tenga las características que le permitan satisfacer las necesidades básicas de las familias, como lo define la agenda internacional denominada Habitat, éstas son: espacio suficiente, seguridad y disponibilidad de servicios, entre otros. Para ello, este trabajo se divide en seis apartados: 1) apuntes teórico-conceptuales sobre la vivienda; 2) desarrollo institucional de atención a la vivienda en México; 3) dinámica de crecimiento de la ciudad de Chihuahua; 4) características de la vivienda tradicional y nueva; 5) oferta de vivienda nueva para el caso particular, y 6) demanda de vivienda. Finalmente se presentan las conclusiones sobre el tema.
\end{abstract}

Palabras clave: vivienda, crecimiento urbano, ciudad de Chihuahua, oferta, demanda.

*El Colegio de la Frontera Norte, A.C., Chihuahua. Correos-e: 1romo@colef.mx; gcordova@ colef.mx; cfuentes@colef.mx y abrugues@colef.mx. 


\section{Introducción}

A partir de la Revolución industrial del siglo XIX, las ciudades empezaron un acelerado crecimiento y el proceso de urbanización se extendió a todo el mundo. En este sentido, el proceso de crecimiento urbano resultante ha experimentado una sucesión de etapas que dependen de la velocidad de los cambios socioeconómicos a favor de las manufacturas y los servicios, y contra el sector primario (Garza et al., 2003: 26). La ciudad que se analiza en este trabajo es la culminación de una forma urbana en la que predomina el beneficio privado, la rentabilidad y el espíritu utilitarista y pragmático, es lo que algunos llaman la anticiudad en la medida que se opone a esos momentos de mayor contenido humanista que caracterizan, entre otras formas urbanas, a la polis, a la comuna medieval y también, en parte, a la ciudad renacentista (Lezama, 1993: 113). Ahora se impone el valor de cambio sobre el valor de uso, donde se privilegia el beneficio del mercado sobre la lógica de la comercialización. Como se observa en la construcción en serie de la vivienda, la cual no se hace a la medida de los moradores, sino que persigue fines de racionalidad económica y la generación de gettos urbanos (Bettin, 1982: 126).

En este contexto, la vivienda constituye uno de los elementos básicos en la determinación de las condiciones de vida de las personas. No sólo es importante la disponibilidad, sino también que se cuente con determinadas características que hagan de la misma un lugar apropiado para el desarrollo de las familias, como lo define la agencia internacional denominado Hábitat ${ }^{1}$. Por ello, en la Segunda Conferencia Mundial sobre Asentamientos Humanos (Hábitat II), llevada a cabo en Estambul, Turquía, en junio de 1996, se enfatiza la importancia de garantizar el ejercicio pleno del derecho a una vivienda, lo que significa algo más que tener un techo bajo el que guarecerse. Significa también disponer de un lugar privado, espacio suficiente, accesibilidad física, seguridad adecuada que incluya servicios de abastecimiento de agua, saneamiento y eliminación de desechos, factores apropiados de calidad del medio ambiente y relacionados con la salud, así como un emplazamiento adecuado y con acceso al trabajo, a los equipamientos urbanos y a los servicios básicos, todo ello a un costo razonable gracias a la intervención estatal. Sin embargo,

${ }^{1}$ El Centro de las Naciones Unidas para los Asentamientos Humanos, mejor conocido como un-Hábitat, es la agencia encargada de la implementación internacional de la Agenda Hábitat (AH) a través de un programa del mismo nombre, así como del monitoreo de la meta 11 de los Objetivos para el Desarrollo del Milenio (ODM), los cuales fueron adoptados por los países miembros de la organización a través de sendas declaraciones en la conferencia de las Naciones Unidas para los Asentamientos Humanos, Hábitat II (1996) y la Cumbre del Milenio (2000). El origen de Hábitat II y la Cumbre del Milenio es una seria preocupación por parte de la onU sobre las problemáticas sociales, económicas y ambientales en el mundo actual y futuro (http://www.unhabitat.org). 
en este misma conferencia surge la Agenda Hábitat (UN-Habitat, 2003), que sigue promoviendo de manera contradictoria la retirada del Estado de los asuntos urbanos. ${ }^{2}$

En el caso que nos ocupa, la vivienda nueva es objeto de estudio del asunto urbano porque nos hace reflexionar sobre las posibilidades reales que tiene la población de contar con condiciones adecuadas, como lo marca la agenda internacional. Para esto es necesario conocer la situación de este tipo de vivienda en una ciudad en franco crecimiento, como Chihuahua.

Este trabajo pretende analizar la intervención estatal y la participación de las fuerzas del mercado inmobiliario en una metrópoli ${ }^{3}$ con alto desarrollo urbano en el norte del país en cuanto a que la población de la ciudad de Chihuahua, Chihuahua, cuente con posibilidades reales de acceder a una vivienda con características que le hagan ser un lugar apropiado para el desarrollo de las familias, como lo marca la agenda internacional. ${ }^{4}$

A últimas fechas, el sistema de gobierno manifiesta que está tratando de fortalecer las vías legales e institucionales para garantizar el acceso a una vivienda digna al sector de la sociedad con baja capacidad adquisitiva, a partir de propuestas basadas en el ingreso de esta parte de la población. Por su parte, el mercado inmobiliario sigue como estrategia general y prioritaria la atención a quienes demandan vivienda para niveles socioeconómicos medio y alto, y sólo atienden a la población de menores ingresos de acuerdo con las normas mínimas de desarrollo de vivienda.

Existen varios aspectos que influyen en el fenómeno de la vivienda nueva, como la creación de reservas de suelo por parte de los gobiernos estatales y de la federación, el crecimiento poblacional y la demanda por la formación de nuevos hogares, la calidad de la vivienda en la ciudad, la acelerada expansión de la superficie urbana, el equipamiento y los servicios urbanos, la oferta de los desarrolladores privados, el tamańo y calidad de las viviendas, la especulación del suelo urbano, entre otros que es perti-

\footnotetext{
${ }^{2}$ En Habitat II se dio la oposición entre aquéllos que piensan que en materia urbana el Estado debe conservar un papel de árbitro, y la tendencia liberal defendida por el Banco Mundial, que plantea que se debe ayudar a los países del sur para que muevan sus recursos propios y a la sociedad civil para participar (Godard, 1998).

${ }^{3}$ La mayoría de los autores que escriben sobre metropolización de las ciudades en México, consideran que cuando una localidad urbana situada en un solo municipio rebasa sus límites y se extiende hacia uno u otros más, adquiere un carácter metropolitano. En un estudio al respecto realizado en los años setenta, se agregaba que debería tener un mínimo de 100,000 habitantes, e identificaba a 12 zonas metropolitanas para 1960, de las cuales únicamente la de la ciudad de México había cumplido una etapa completa de metropolitanismo (Unikel et al., 1976). Actualmente se consideran metrópolis aquellas ciudades con más de 500,000 habitantes, independientemente de que se hayan o no extendido hacia otros municipios (Garza, 2001: 95).

${ }^{4}$ Lo que aquí se presenta es parte de los resultados del reporte técnico Córdova et al., 2006.
} 
nente abordar. Con todo esto surgen inquietudes como: ¡el Estado está realizando las acciones conducentes para garantizar el acceso a una vivienda digna para todos los habitantes de la ciudad?, jes sensible el mercado inmobiliario a las necesidades sociales de sus clientes en términos de calidad de vivienda, equipamiento y servicios urbanos?

La respuesta a estas preguntas se da en los siguientes seis apartados. El primero establece algunos apuntes teórico-conceptuales sobre la vivienda; el segundo es un recuento general del desarrollo institucional de atención a la vivienda en México; en el tercero se observa la dinámica de crecimiento de la ciudad de Chihuahua; en el cuarto se hace un diagnóstico de las características de la vivienda tradicional en la ciudad y de los fraccionamientos nuevos; el quinto se refiere a la vivienda nueva que se oferta en el área de estudio; y el último apartado se ocupa de la demanda de vivienda respecto a la necesidad por formación de hogares, migración, renta y tamaño de las familias.

\section{Apuntes teórico-conceptuales sobre la vivienda}

El problema de la vivienda en América Latina se enmarca en un proceso de industrializacion que tiene un componente eminentemente urbano, y atrae a una gran cantidad de migrantes de las zonas rurales en busca de mejores condiciones de vida. El problema de hacinamiento y salubridad de la clase trabajadora se acentuó a partir de la pauperización de la fuerza trabajadora, la pérdida de poder adquisitivo, las altas tasas de interés que no permitían que amplios sectores de la población pudieran acceder a financiamientos, altas tasas de inflación que encarecían el precio de los productos de la construcción, etc. Lo anterior generó un crecimiento de las áreas que se ocuparon a través de la invasión de suelo urbano, la expansión anárquica de los límites urbanos, la destrucción de los recursos naturales, el incremento del desempleo y del subempleo, el comercio callejero ilegal, el deterioro de los sistemas de transporte público, el déficit de servicios públicos y un rápido proceso de urbanización (Pradilla, 1982).

La construcción de vivienda es obra de tres sectores: el privado formal, el privado informal y el público. El sector privado formal produjo vivienda para estratos de ingresos medios y altos. El modelo de conjunto o fraccionamiento cerrado se convirtió en una manifestación recurrente de este tipo de producción de vivienda, que desarrollan inmobiliarias y constructoras privadas que buscan calidad edilicia y seguridad, así como autosuficiencia y tranquilidad. Esta forma de vivienda tiene repercusiones en el proceso de fragmentación urbana que viven las ciudades en el mundo. 
El sector privado informal construye vivienda progresiva o autoconstruida ante la imposibilidad económica de acceder a la propiedad del suelo o programas de vivienda social en terrenos gestionados de manera informal. Las consecuencias de este tipo de construcción son funestas. En general los suelos ocupados carecen de las condiciones mínimas para el proceso de urbanización y para la construcción de vivienda, ya que usualmente son zonas de alto riesgo de inundaciones, deslizamiento de laderas, etc. A este proceso le sigue la legalización de los terrenos, lo cual contraviene lo establecido en el marco normativo de asentamientos humanos.

El sector público construye vivienda por medio de la gestión institucional, para lo cual ha desarrollado distintos programas a lo largo del siglo Xx y principios del xxI. El sector público participa en la construcción de vivienda desde el primer cuarto del siglo xx y su acción se puede caracterizar en cuatro grandes periodos.

Desde 1925 y hasta principios de la década de los cincuenta el Estado mexicano inicia la asistencia gubernamental directa al problema habitacional con la creación de organismos públicos, como la Dirección de Pensiones Civiles, el Banco Nacional Hipotecario Urbano y de Obras Públicas -antecedente de Banobras- y el Banco de Fomento a la Vivienda, mientras que el Instituto Mexicano del Seguro Social (IMss) realizaba programas de vivienda en arrendamiento.

En los años cincuenta y sesenta, la manera de abordar la problemática social de la vivienda evoluciona a otra fase. En esta etapa se da un paso adelante en la integración de una política nacional (Salcedo, 2000).

La problemática de la vivienda en los años setenta y ochenta transita a una fase más estructural. El cambio se explica a partir de la necesidad de dimensionar y diversificar los alcances de la institucionalidad en función de tres tendencias básicas que estaban influyendo de manera importante: la movilidad del campo a la ciudad, con el consecuente crecimiento desordenado de las ciudades; el acelerado aumento poblacional y las crecientes carencias económicas de amplios grupos sociales.

En los noventa el Estado cambia nuevamente su papel en la vivienda, deja de construir para concentrar sus esfuerzos en la coordinación sectorial y promoción habitacional. En 1993 los organismos de cobertura nacional se reestructuran para regresar a su origen eminentemente financiero, sin perder la vocación social, y para promover la integración del mercado habitacional (Fuentes y Peña, 2006). En el año 2000 se implementó el Programa Sectorial de Vivienda (2000-2006), cuyo objetivo fue desarrollar un mercado habitacional articulado y eficiente que brindara el anhelado acceso a vivienda por parte de la población.

A partir de este marco referencial, la consecución del objetivo planteado en este trabajo, analizar el papel del gobierno y del mercado inmo- 
biliario en relación con la disponibilidad de vivienda nueva en la ciudad de Chihuahua en el periodo 2000-2005, se logra mediante el siguiente procedimiento metodológico.

Se utilizaron diversas fuentes de información: $a$ ) datos por área geoestadística básica (AGEB) de los censos poblacionales del INEGI; $b$ ) se realizaron entrevistas a profundidad a actores clave subdividos en cuatro grupos: actores de la lógica de la ganancia, del bienestar, de la necesidad y del conocimiento, y c) se aplicó una encuesta aleatoria y territorializada.

Para realizar la encuesta se clasificó la vivienda en tres tipos de acuerdo con el periodo en que se estableció en la ciudad de Chihuahua. La categorización queda de la siguiente manera: vivienda de los barrios tradicionales que se refiere a las colonias más antiguas donde se aplicaron 80 cuestionarios; le correspondieron 150 cuestionarios a los fraccionamientos nuevos construidos en el quinquenio 2000-2005; y aquella localizada en el resto de la ciudad que implicó la aplicación de 220 cuestionarios (plano I).

Las personas encuestadas fueron los jefes de hogar en su domicilio particular durante los meses de agosto y septiembre de 2006, con el objetivo de tener la percepción del usuario respecto a la vivienda en cuanto a disponibilidad y calidad, así como la infraestructura y el equipamiento urbano existente, y a su vez conocer la forma en que se integran a la estructura urbana a partir de la ubicación de su residencia.

\section{Desarrollo institucional de atención a la vivienda en México}

En México el desarrollo institucional de atención a la vivienda ha pasado por cuatro grandes etapas: antes de 1988, 1988-1994, 1994-2000 y 2000 a la fecha.

La primera etapa se caracterizó por una importante regulación del Estado en la producción y distribución de la vivienda con el fin de reactivar el aparato productivo y promover el empleo (Coulomb, 1989), y por una influencia poco decisiva del sector privado y agencias internacionales en el sector. Durante este periodo, al Estado lo representaron el Fondo de la Vivienda del Instituto de Seguridad y Servicios Sociales de los Trabajadores del Estado (Fovissste), ${ }^{5}$ el Fondo Nacional de Habitaciones Popula-

${ }^{5}$ El Fovissste se creó el 10 de noviembre de 1972, se publicó en el Diario Oficial de la Federación (DOF) el decreto que reforma el inciso f, fracción XI, apartado b del artículo 123 Constitucional para quedar en los siguientes términos: “...el Estado mediante las aportaciones que haga, establecerá un fondo nacional de la vivienda a fin de constituir depósitos en favor de dichos trabajadores y establecer un sistema de financiamiento que permita otorgar a éstos crédito barato y suficiente para que adquieran en propiedad habitaciones cómodas e higiénicas, o bien para construirlas, repararlas, o mejorarlas o pagar pasivos adquiridos por estos conceptos", <http://www.Fovissste.gob.mx/wb/Fovi/ Fovi_QEFov>, 12 de julio de 2010. 


\section{Plano I}

\section{Distribución de la vivienda de acuerdo con el año de su construcción en la ciudad de Chihuahua}

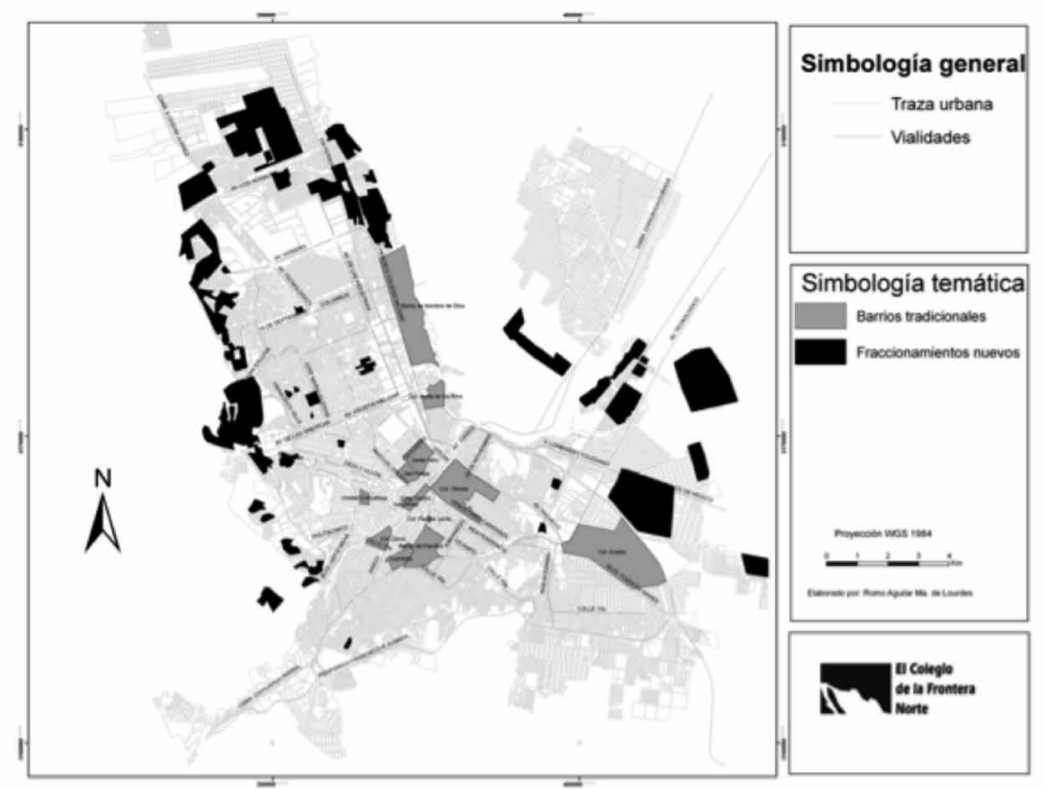

Fuente: Elaboración propia.

res (Fonhapo), el Instituto del Fondo Nacional de la Vivienda para los Trabajadores (Infonavit) y el Fondo Operacional para la Vivienda (Fovi). El primero no funcionó en su misión de atender a los pobres (Villavicencio, 1997), y al final de este periodo se advierte la incapacidad del Estado para resolver el problema de la vivienda en las ciudades del país (Moreno, 1989), entre otras cosas, por la lenta burocracia estatal y la flexibilidad para ajustar los intereses del sistema corporativo, centrales obreras oficiales y demás prácticas del sistema político mexicano (Pozas, 1989).

La segunda etapa se distinguió por una tendencia del Estado a la desregulación del sector, ${ }^{6}$ permitiendo una mayor intervención de los agentes privados financieros y constructores, la cual se dio bajo una fuerte influencia del enfoque facilitador promovido por el Banco Mundial (Puebla, 1999; Ímaz y García, 1997). El discurso oficial era que la magnitud del problema no podía resolverse con los limitados recursos tanto del sector público como de los mismos necesitados (Coulomb, 1989). Sin embargo, esta reforma no buscó una mayor articulación entre la sociedad

${ }^{6}$ El Programa Especial para el Fomento y Desregulación de la Vivienda (1993-1994) es fundamental para analizar la reorientación ideológica y programática de la política de vivienda (Ímaz y García, 1997). 
y el Estado, ni que los cambios fueran asumidos socialmente mediante la participación en las decisiones y el amplio consenso.

En la tercera etapa inicia la desregulación y la descentralización ante la crisis que representa la falta de cuando menos cuatro millones de viviendas y una demanda anual de más de 700,000 mil viviendas (Capiu, 1999). A partir de la crisis de 1994 se pueden distinguir dos elementos que han trastocado el sistema de producción de la vivienda en México: 1) la flexibilidad en los procesos de producción en la que se involucra una subcontratación laboral, transfiriendo los altos costos a los contratistas, y 2) la liberalización del capital, en que se da la vinculación del sector de la vivienda con el sector financiero (Álvarez, 1999).

En el ámbito de la política federal se encuentran las reformas a la Ley del Seguro Social para crear las Administradoras del Fondo para el Retiro (Afores) y las Sociedades de Inversión Especializadas de Fondos para el retiro (Sifores) y que se vincula con una cuenta a la reforma del Infonavit; en la tenencia de la tierra encontramos la viabilidad a la privatización de la propiedad social, con los cambios al artículo 27 constitucional, a pesar de que éstas no tratan de influir en el mercado del suelo urbano (Álvarez, 1999).

La cuarta etapa (ańo 2000 a la fecha) marca la apertura tanto de la construcción como del financiamiento al libre mercado de la vivienda. En este periodo encontramos la ampliación del crédito a casi todos los segmentos de la población, el financiamiento particular -vía bancos-, Sofoles y cajas de ahorro, y los grandes proyectos de inversión del gobierno federal. Se observa ahora un apoyo nunca visto de los gobiernos federal y estatal, e incluso los gobiernos municipales han entrado a esquemas de apoyo a este sector. El presupuesto del gobierno federal para vivienda nueva en el año 2007 fue de aproximadamente 4,000 millones de pesos (mdp), más los 3,000 mdp del Fonhapo. ${ }^{7}$ Por su parte, el gobierno del estado de Chihuahua junto con el Infonavit tuvieron como meta realizar 40,000 acciones de vivienda para ese mismo año, con una inversión conjunta de 6,500 millones de pesos (Quezada, 2007).

La política de fortalecer la vivienda se encuentra en una etapa madura, si consideramos que nunca antes en un sexenio (2000-2006) se había avanzado tanto en este sector, donde se entregaron tres millones de créditos habitacionales. El gobierno de Felipe Calderón Hinojosa ha anunciado que llegará a los seis millones de créditos en su periodo de seis años (2006-2012).

\footnotetext{
${ }^{7}$ Este fondo se destina a los segmentos de población con ingresos menores a dos salarios mínimos, otorga hasta $20 \%$ del enganche de viviendas con un costo aproximado de 150,000 pesos. En 2006, el Fonhapo aportó cerca de 5,000 subsidios en el estado de Chihuahua, y en 2007 esperaba colocar al menos 6,000 subsidios con un promedio de 30,000 pesos cada uno (Quezada, 2007).
} 
Para cumplir estas metas se han consolidado varias instituciones, como el Fovi, incluyendo el Programa de Subsidio y Ahorro para la Vivienda (Prosavi), el fortalecimiento de programas de vivienda a través de la Secretaría de Desarrollo Social (Sedesol), Fonhapo, ${ }^{8}$ y en el ámbito estatal el Instituto de la Vivienda del Estado de Chihuahua (Ivi), cuyo objetivo principal es promover la vivienda para la población de menores ingresos. También se crearon organismos como la Sociedad Hipotecaria Federal (shF), la Comisión Nacional de Fomento a la Vivienda (Conafovi), denominada actualmente Comisión Nacional de Vivienda (Conavi).

Estas modificaciones nos demuestran que el Estado mexicano sigue siendo subsidiario, al igual que algunos gobiernos del mundo, ${ }^{9}$ en tanto que los beneficios gubernamentales modifican los factores del mercado y su asignación a la demanda porque se dirigen a los sectores más desprotegidos mediante un instrumento netamente técnico. El Estado reconoce la importancia de la inversión en la vivienda de interés social y para las clases más desprotegidas en la economía de mercado no sólo como un bien mercantil, sino como un instrumento para inyectar recursos a la economía. Es el propio Estado quien interviene en el proceso para organizar la producción, manteniendo el control tanto en el ámbito financiero como en las características de la vivienda, lo que acentúa el rol centralista de la política pública sobre la producción de la vivienda.

\section{Dinámica de crecimiento poblacional y urbano de la ciudad de Chihuahua}

A lo largo de su historia, la ciudad de Chihuahua ha mostrado un acelerado crecimiento demográfico que se ha traducido en un rápido proceso de urbanización. Del año 1970 a 2005 la población casi se triplicó: pasó de 277,099 habitantes a 713,613. Sin embargo, el crecimiento poblacional muestra una tendencia hacia la estabilización que se refleja en la disminución de la tasa de crecimiento poblacional que ha pasado de 5.5\% en 1970 a $1.6 \%$ en el año $2005 .{ }^{10}$ La población de la ciudad pasa por un proceso de transición demográfica al que contribuye el descenso de la fecundidad, el aumento de la esperanza de vida y la reducción de la tasa

\footnotetext{
${ }^{8}$ El caso Fonhapo es una expresión del progresivo desarrollo y formalización de programas sociales focalizados en México (Duhau, 1997).

${ }^{9}$ El gobierno español, en el Plan de Suelo y Vivienda 1998-2001, propone como metas la facilitación de viviendas a las clases con ingresos medios y bajos del acceso a la primera vivienda y las ayudas estatales a jóvenes, tercera edad, minusválidos y familias numerosas. Se observa un alejamiento en la producción de vivienda y se enfoca a un papel regulador y de asistencia discreta y temporal (Morillo, 2004).

${ }^{10}$ Reporte técnico Córdova et al. (2006).
} 
de crecimiento natural de la población. Sin embargo, la ciudad continúa experimentado aumento en el número de habitantes vía migración.

$\mathrm{El}$ incremento de la mancha urbana se aceleró sobre todo a partir de la década de los noventa. Durante el periodo 1980-2005 la superficie urbana creció más del doble, es decir, pasó de 8,489 a 19,024 ha. En los últimos años el crecimiento urbano se dio en forma de anillos concéntricos en un primer momento para posteriormente expandirse sobre los principales ejes carreteros, sobre todo hacia el norte. ${ }^{11}$

El aumento de la población, acompañado de un acelerado crecimiento de la superficie urbana, ha originado un patrón de localización disperso, que se manifiesta en la disminución gradual de la densidad de población, que pasó de 67.35 habitantes por hectárea (hab/ha) en 1970 a 37.51 en el año 2005 (cuadro 1).

\section{Cuadro 1}

Tasas de crecimiento poblacional de Chihuahua, 1970-2005

\begin{tabular}{cccccc}
\hline Año & $\begin{array}{c}\text { Población } \\
\text { total }\end{array}$ & $\begin{array}{c}\text { Tasa de } \\
\text { crecimiento } \\
\text { poblacional }\end{array}$ & $\begin{array}{c}\text { Superficie } \\
\text { urbana (ha) }\end{array}$ & $\begin{array}{c}\text { Densidad de } \\
\text { población } \\
\text { (hab/ha) }\end{array}$ & $\begin{array}{c}\text { Variación } \\
\text { \% densidad }\end{array}$ \\
\hline 1960 & 150,430 & & & & \\
1970 & 257,027 & 5.5 & $3,815.78$ & 67.35 & \\
1980 & 385,603 & 3.9 & $8,489.16$ & 45.42 & -32.6 \\
1990 & 516,153 & 3.0 & $15,097.91$ & 34.18 & -24.7 \\
1995 & 613,722 & 3.0 & $16,515.04$ & 37.16 & 8.7 \\
2000 & 657,876 & 1.6 & $18,055.04$ & 36.43 & -2.0 \\
2005 & 713,613 & 1.4 & $19,024.07$ & 37.51 & 3.0 \\
\hline
\end{tabular}

Fuente: Elaboración propia a partir de INEGI-SPP, 1986; INEGI, 1992, 1997, 2002, 2009.

La densidad de población de la ciudad de Chihuahua no es homogénea en toda el área urbana. En 1990 la densidad poblacional promedio en la ciudad fue de 34.18 hab/ha. Las densidades más bajas (menos de 14) se ubican sobre la carretera a Ciudad Juárez, al poniente, en los alrededores del aeropuerto y hacia el suroriente, en la salida a la carretera a Cuauhtémoc. Las densidades bajas (17.4 a 49 hab/ha) se localizaron en el centro de la ciudad y al surponiente en dirección a la salida a la carretera a Delicias. Las densidades medias (46.8-78.2) y alta (78.9-123.7) se ubicaron hacia el norte y surponiente. Las áreas más densamente pobladas (135.9 a $204 \mathrm{hab} / \mathrm{ha}$ ) se encontraron en las colonias que rodean el Parque Industrial Saucito, hacia el norte de la ciudad. ${ }^{12}$ 
En el año 2000 se observó con claridad el proceso de reacomodo poblacional, que implica la pérdida de población de la zona central y la densificación en zonas alejadas del centro principal, sobre todo en el extremo norte. Las áreas que mantienen una baja densidad ( 0 a 17 hab/ha) son las zonas residenciales localizadas al poniente, así como los extremos sur poniente y sur oriente. Los sectores de densidad media (48 a 77 hab/ ha) se ubican alrededor del centro histórico, los cuales muestran una pérdida paulatina de población.

El extremo norte es el que presenta con mayor claridad un incremento de la densidad de población como resultado de que hacia allá se han dirigido los programas de vivienda popular. Dichas áreas habitacionales han cambiado de densidad baja (0 a 17) a alta (78-129 hab/ha), sobre todo en los fraccionamientos cercanos a la carretera que comunica a Chihuahua con Ciudad Juárez. De 1990 al año 2000 se observa que el centro de la ciudad está viviendo el típico proceso de expulsión de población hacia la periferia, característico de las ciudades que muestran un modelo de crecimiento extensivo de la superficie urbana, como las de Estados Unidos y Australia.

\section{Características cualitativas de la vivienda tradicional y nueva}

En el año 2000 los indicadores de precariedad a nivel de los municipios urbanos del norte del país muestran mayores rezagos que el promedio nacional. En ciudades como Nogales, Mexicali, Tijuana y Ciudad Juárez más de la mitad de los techos de sus viviendas son de materiales frágiles (lámina, cartón, etc.), en cambio, la ciudad de Chihuahua apenas cuenta con $17.6 \%$ de este tipo de techos, con lo que supera al promedio nacional que es de 29.6\% (Fuentes y Peña, 2006). En términos de calidad de la vivienda, Chihuahua tiene un desempeño modesto con un índice de calidad ${ }^{13}$ de la vivienda de $75.9 \%$, y que la ubica en el lugar 26 de 39 ciudades de más de 100,000 habitantes estudiadas en el país (García, 2006).

Lo anterior es en cuestión de indicadores estructurales sobre la vivienda, pero ¿qué es lo que opinan quienes la habitan? Para atender esta pregunta se aplicó una encuesta aleatoria con respecto a la vivienda en tres áreas de la ciudad: una en los fraccionamientos nuevos, otra en lo que se denominó vivienda tradicional (o barrios antiguos), y la tercera en el resto de la ciudad. El objetivo de dicha encuesta es conocer la percepción de quienes habitan la vivienda con respecto a la misma y al equipamien-

\footnotetext{
${ }^{13}$ El indicador se refiere al porcentaje de viviendas con materiales frágiles en relación con el total de viviendas.
} 


\section{Plano II \\ Fraccionamientos nuevos autorizados entre los ańos 2000 y 2005 en Chihuahua}

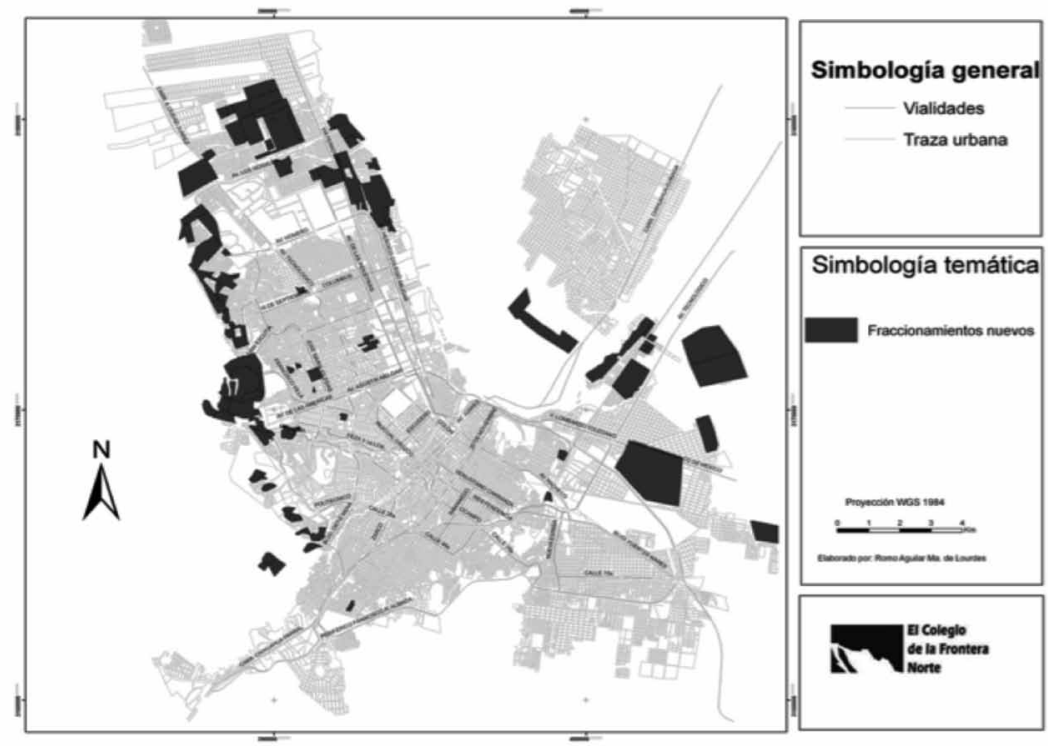

Fuente: Elaboración propia con base en información proporcionada por el Instituto Municipal de Planeación, Chihuahua.

to urbano existente, así como actualizar la información sobre las condiciones en que viven y la forma en que se integran a la estructura urbana. ${ }^{14}$

En los fraccionamientos construidos entre los años 2000 y 2005 (plano II) los resultados muestran que los jefes de hogar manifestaron que el promedio de residencia es de 6.27 años en los fraccionamientos nuevos y 25.89 años en la ciudad en general.

Por otro lado, $90.54 \%$ de los jefes de hogar manifestaron ser dueños de la vivienda nueva que habitan un promedio de 3.71 personas y está conformada por 4.71 cuartos en promedio, excluyendo baños; al respecto, $66 \%$ manifestó que contaba con un solo baño, teniendo un promedio de 1.57 baños.

En cuanto al tipo de materiales, $64.60 \%$ manifestó que las paredes de su vivienda son de bloque de cemento y $35.69 \%$ de ladrillo. Asimismo, 50.68\% tienen piso de cerámica, 27.03 de concreto, 14\% de linóleo, y el resto de otros materiales. En cuanto al techo, $95.95 \%$ dijo que cuentan con techo de cemento en su vivienda nueva.

En un análisis comparativo de los resultados de las tres encuestas se observa que hay diferencias marcadas en cuanto al desarrollo de la vivienda y la forma de ocupación de la misma. Los residentes de los fracciona-

\footnotetext{
${ }^{14}$ Esta encuesta forma parte del proyecto Córdova et al. (2006).
} 
mientos con vivienda nueva en comparación con los residentes de barrios tradicionales, en general son dueños de la vivienda y aparentemente viven en mejores condiciones: con más baños y materiales de construcción resistentes, aunque enfrentan mayor grado de hacinamiento y se encuentran determinados a pagar más por concepto de energéticos, para enfrentar las condiciones climáticas de la región al vivir en casas construidas con bloque (cuadro 2).

\section{Cuadro 2}

Características de las viviendas en la ciudad de Chihuahua

\begin{tabular}{lccc}
\hline $\begin{array}{l}\text { Lugar de aplicación } \\
\text { de la encuesta }\end{array}$ & $\begin{array}{c}\text { Barrios tradicionales } \\
\text { (más antiguos, centro } \\
\text { principal) }\end{array}$ & $\begin{array}{c}\text { Alrededor } \\
\text { del centro } \\
\text { principal o } \\
\text { centro histórico }\end{array}$ & $\begin{array}{c}\text { Fraccionamientos } \\
\text { nuevos }\end{array}$ \\
\hline Varacterísticas & $80.5 \%$ & $83.40 \%$ & $90.5 \%$ \\
Númenda propia & 1.54 & 1.3 & 1.57 \\
Paredes de bloque & $14.08 \%$ & $38.89 \%$ & $64.43 \%$ \\
Techo de cemento & $82.00 \%$ & $94.15 \%$ & $95.95 \%$ \\
Habitantes por vivienda & 3.14 & 3.73 & 3.71 \\
Núm. de cuartos & 5.46 & 4.64 & 4.71 \\
(excepto baños) & 0.57 & 0.8 & 0.78 \\
Habitantes por cuarto & \multicolumn{3}{|}{} \\
\hline
\end{tabular}

Fuente: Elaboración propia.

Respecto a la opinión de los expertos en desarrollo urbano y de vivienda de la ciudad, los profesionistas y los académicos aseguran que el problema de la calidad se relaciona con el nivel socioeconómico de quienes la habitan, ya que señalan que entre menores ingresos, las viviendas son mayormente castigadas en su tamaño. En cambio, los desarrolladores lo asocian con los costos de urbanización, pues afirman que esto último es lo que castiga el tamaño de la vivienda.

Yo diría que la vivienda cada vez es más inhabitable, y las características de la vivienda que las personas en general pueden adquirir, entre más bajos ingresos, son más evidentes: las dimensiones se han reducido y también las características de confort, vamos, las viviendas son cada vez más pequeñas y los lotes también son demasiado pequeños, pero además los materiales de construcción las hacen calientes en verano y frías en invierno, son ruidosas (entrevista con el director de Estudios Urbanos, S.A., 23 de agosto de 2006). ${ }^{15}$

${ }^{15}$ Todas las entrevistas que se señalan en este artículo se encuentran en Córdova et al. (2006). 
De hecho, los desarrolladores afirman que tienen buena calidad de vivienda y que el tamaño de la misma tiene que ver con los límites del crédito que se otorga a los derechohabientes, así como con los costos de urbanización e infraestructura para agua, drenaje, cableado eléctrico subterráneo, además del incremento en el costo de los materiales que no es proporcional con el incremento del salario mínimo. ${ }^{16}$

\begin{abstract}
Urbi hace la vivienda con calidad, no hay duda, tienen de los mejores estructuristas [sic], todo se hace con calidad. El hecho de que baje el precio va contra la utilidad, no contra la calidad. Se puede aparentar ver eso, se está dando aquí en Chihuahua donde no se hacían viviendas económicas de dos recámaras, nosotros las hacemos. Pero no es esfuerzo sólo de Chihuahua, en otras por partes del país se hace desde hace mucho tiempo, y a 173,000 pesos, en la ciudad de Coahuila [sic] se están vendiendo casas de $50 \mathrm{~m}^{2}$ como económica, pero es el valor de la tierra, intervienen otros factores. Por supuesto que tienen que ver los costos de urbanización. No es algo exento en Chihuahua, esto es en toda la República. Es un mercado que se está dando natural, tienes que darle más a la gente. La vivienda que tiene dos recámaras se está haciendo de $38 \mathrm{~m}^{2}$. Pero estás dando más, que prefiere una familia de 4 o 5 personas, yo creo que es más digno separar a los niños de los padres". ${ }^{17}$
\end{abstract}

Finalmente resaltamos que en la encuesta a hogares en fraccionamientos nuevos, los jefes de hogar califican a la vivienda con 7.66 puntos en una escala de 1 a 10, manifestando que lo más atractivo de la vivienda que compraron es en este orden: las instalaciones eléctricas e hidráulicas y la calidad de los techos; en cambio, lo menos atractivo es el diseño del conjunto sala, cocina y comedor.

En cuanto al precio que se pagó en los fraccionamientos de reciente creación, a la mitad de los jefes de hogar encuestados les parece accesible, y a la otra parte, alto o muy alto. Asimismo, $77.4 \%$ considera que las alternativas de conseguir vivienda nueva en la ciudad en general son buenas.

También se pudo observar que los jefes de hogar tanto en los barrios tradicionales como en los fraccionamientos nuevos y en el resto de la ciudad, tienen más confianza en las instituciones públicas de vivienda (Infonavit, Ivi, etc.) que en las empresas privadas. El 57.8\% de los encuestados confía poco o nada en las garantías establecidas en la venta de la vivienda, ya sea pública o privada.

De acuerdo con la respuesta de los jefes de hogar encuestados, el principal factor que motivó el cambio de domicilio en el caso de fraccionamientos nuevos es el no pagar renta y tratar de tener una vivienda propia, seguido por el crecimiento de su familia. Los factores del medio ambiente urbano con los que se identifican más son, en este orden: el

\footnotetext{
${ }^{16}$ Presidente de Canadevi, entrevista, 18 de septiembre de 2006.

${ }^{17}$ Director de Urbi, s.A., entrevista, 22 de septiembre de 2006.
} 
entorno donde se encuentra asentada su vivienda nueva, la limpieza del lugar, el acceso al parque público, la disponibilidad de agua, la disminución de riesgo a desastres naturales y la mejor calidad del aire.

Los factores que motivan la permanencia en el domicilio en barrios tradicionales son, en este orden: la costumbre, la cercanía al centro de la ciudad y al trabajo. Los factores del medio ambiente urbano con los que se identifican más son, en este orden: el paisaje, la limpieza del lugar, la disponibilidad de agua y que no hay riesgos de desastres naturales.

\section{Oferta de vivienda nueva}

La oferta de vivienda en la ciudad en el año 2005 se encontraba distribuida en tres sectores y 130 fraccionamientos con 1,877 viviendas en total entregadas, 2,345 por entregar, 970 casas en construcción y 3,110 lotes urbanizados. Esto representaba aproximadamente $80 \%$ de la actividad desarrollada. Para el año 2006 se contabilizaron ocho fraccionamientos adicionales localizados al noroeste de la ciudad, 30 desarrollos en el sector sur y 12 al oriente y surponiente (Córdova et al., 2006).

De acuerdo con información proporcionada por el Instituto de la Vivienda de Chihuahua (Ivi), en los últimos cinco años se han construido 2,321 viviendas con créditos Vivah ${ }^{18}$ para sectores con ingreso de dos a tres salarios mínimos (cuadro 3).

\section{Cuadro 3 \\ Créditos del Programa Vivah-tu Casa en la ciudad de Chihuahua}

\begin{tabular}{clc}
\hline Año & \multicolumn{1}{c}{ Fraccionamiento } & $\begin{array}{c}\text { Número de } \\
\text { viviendas }\end{array}$ \\
\hline 2001 & Mineral II & 639 \\
2002 & Jardines del Sacramento & 411 \\
2003 & Sahuaros & 35 \\
2004 & Francisco R. Almada & 336 \\
& Jardines del Sacramento & 55 \\
2005 & Rinconada los Nogales & 100 \\
& Rinconada los Nogales II & 570 \\
$2001-2005$ & Rinconada los Nogales III & 175 \\
\hline
\end{tabular}

Fuente: Elaboración propia a partir de la información proporcionada por el Instituto de la Vivienda del estado de Chihuahua en el ańo 2006.

${ }^{18}$ Según la Conafovi, en 2001 el programa Vivah dio apoyo económico a 17,655 familias; en noviembre de 2002 había dado 21,491 subsidios (www.conaFovi.gob.mx), 5 de noviembre de 2006. 
En el año 2006, el gobierno del estado contaba con 767 hectáreas, localizadas principalmente al norte y al este de la ciudad. Esta reserva constituye casi dos veces más la necesidad de reserva para vivienda y equipamiento urbano proyectada para el año 2010.

Según entrevista con funcionarios del Ivi, la política del instituto es adquirir reservas, que luego oferta con productores de vivienda, con el fin de controlar precios de suelo e incluir otros usos complementarios y desarrollos mixtos. Esto significa que en casi dos terceras partes de estas reservas cubrirán la demanda de suelo necesaria para otros tipos de crédito en el año 2010. Hay que señalar, sin embargo, que la política seguida por el gobierno del estado va contra las reglas del Banco Mundial, que aboga por liberar el mercado de suelo y dejar su desarrollo a la oferta y demanda.

Esta acción forma parte del programa de vivienda de coparticipación propuesto en el Programa Institucional de Vivienda (Ivi, 2004: 68), donde el gobierno del estado a través del Ivi adquiere reservas territoriales y urbaniza suelo a menor costo, para la construcción de conjuntos habitacionales mediante convenios con promotores privados, donde se otorgan facilidades para la operación de compra-venta con el fin de coadyuvar a mitigar el problema de la falta de vivienda, facilitando la aplicación de créditos Infonavit y Fonhapo, vía Sedesol, así como la aplicación de créditos para viviendas económica y tradicional.

No obstante lo anterior, las reservas del Ivi se caracterizan por inducir la expansión de la mancha urbana porque se ubican fuera del límite del área urbanizable según el Plan Director del año 2000, e inducen el cambio de uso de suelo en zonas no urbanizables, si consideramos que se ubican en las zonas donde según el Plan de Desarrollo Urbano son de preservación ecológica, o en zonas con uso de suelo de vivienda tipo granja en la vera del río Sacramento (cercanos a la vialidad ribereña que actualmente se construye) ${ }^{19}$ (plano III). Esta situación puede llegar a fomentar aún más la dispersión urbana, si no se prevé la dosificación adecuada de reservas para vivienda para el resto de los promotores de vivienda, así como la generación de zonas marginadas o aisladas, si se considera que la población que vivirá en estos asentamientos demandará transporte, equipamientos y servicios, que al estar alejados del área urbana aumentan el costo de marginalidad.

Por otro lado, los créditos son un tema que merece discusión. De acuerdo con algunos actores entrevistados, los mayores créditos ofertados son los de Infonavit, que cuenta con tres o cuatro tipos: para vivienda económica, vivienda de bajo ingreso y vivienda tradicional; para la pri-

${ }^{19}$ De las reservas disponibles del Ivi, sólo dos de ellas ha sido aprobadas en un plan parcial. 


\section{Plano III}

\section{Reservas del Ivi en la ciudad de Chihuahua}

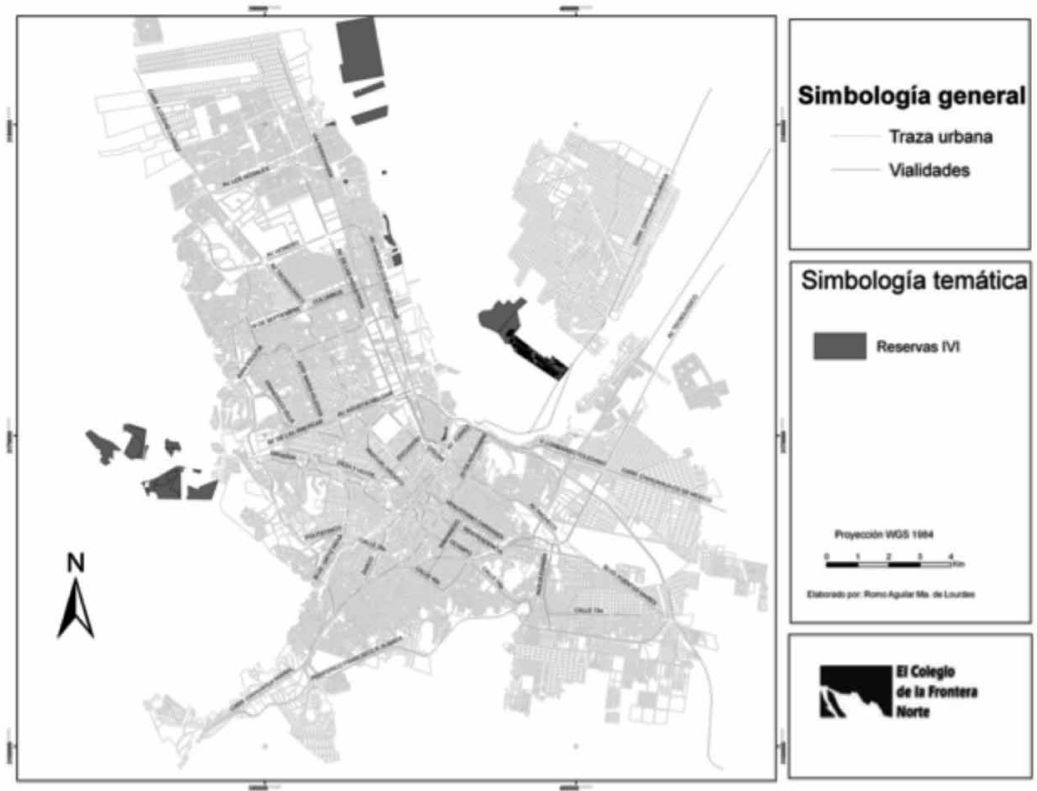

Fuente: Elaboración propia a partir de información proporcionada por Instituto Municipal de Planeación, Chihuahua.

mera otorga hasta 173,000 pesos, para la segunda alrededor de 190,000 y para la tercera es de hasta 300,000 pesos.

Las empresas líderes en construcción de vivienda son Urbi, Ruba, Finsa y CTU. Las primeras tres son las que construyen la mayor cantidad de vivienda de interés social. Aún cuando Ruba no ha dado la cifra exacta, menciona que la mayor demanda es para la construcción de vivienda económica dirigida a $70 \%$ de la población que gana menos de cuatro salarios mínimos, y construyó 1,500 viviendas en 2005 y 1,651 en 2006, de las cuales $60 \%$ corresponde a vivienda económica, 20\% de interés social (costo de 190,000 o 200,000 pesos) y 20\% está en vivienda media (300,000 pesos); y del total de las ventas, $80 \%$ ha sido vendido mediante créditos Infonavit (Ruba, 2006).

En el caso de Urbi, programó para 2006 la construcción de 1,121 viviendas, de las cuales $36 \%$ es económica, $14 \%$ viviendas que tienen un precio entre 180,000 y 380,000 y el $50 \%$ restante se refiere a vivienda residencial. ${ }^{20}$

${ }^{20}$ Director de Urbi, entrevista, 22 de septiembre de 2006. 
De acuerdo con el Ivi y con Infonavit, se tiene contemplada la construcción de 100,000 viviendas para antes de que termine el gobierno de José Reyes Baeza en el año 2010, de las cuales 60,000 las desarrollará el sector privado y 40,000 institucionales (gobierno); se planea construir $60 \%$ en Ciudad Juárez, 30\% en la capital, y el restante $10 \%$ en localidades de Nuevo Casas Grandes, Parral, Camargo y Jiménez (Infonavit, 2006).

El Ivi está trabajando principalmente para la población con ingresos en el rango de dos a tres salarios mínimos. En el rango menor a dos salarios mínimos se están promoviendo los subsidios de Fonhapo o el Programa Tu Casa, que atiende el rango de 1-3.9 salarios mínimos. De acuerdo con el Infonavit (2006), el estado de Chihuahua es el que concede más créditos para vivienda económica en el país. De acuerdo con este instituto, 65\% de los créditos en el estado se destinan a este tipo de vivienda, la cual está directamente relacionada con los principales ingresos de los trabajadores, ya que $85 \%$ gana menos de cuatro salarios mínimos, por ello también el subsidio de Fonhapo está siendo más demandado por la entidad. Asimismo, la construcción de vivienda se incrementó en 300\% en el periodo 2000-2006. En el año 2000 se otorgaron 12,000 créditos, y en 2007 se esperaba llegar a los 36,000.

En cuanto a la oferta de suelo para vivienda, la mayor parte de los actores afirman que el problema del suelo es su encarecimiento y la especulación por pocos dueños. Un ejemplo de esto es el sur de la ciudad, con un territorio de propiedad ejidal. Aunado a esto se da el fenómeno de intermediación: "La mayor parte de las empresas adquieren terrenos, es muy raro que la adquieran de manera directa con los ejidatarios, casi siempre se adquieren a través de intermediarios" (Canadevi, 2006); también los desarrolladores negocian con el Ivi y de manera directa con dueños del suelo.

Cabe mencionar que para el Infonavit el problema está solucionado con la adquisición de reservas por parte del gobierno del estado. ${ }^{21}$ Sin embargo, la ubicación de las mismas, alejadas de la mancha urbana fomenta la expansión y bajas densidades. Asimismo, algunas de estas reservas carecen de planes parciales y se ubican en zonas no aptas para vivienda económica por las pendientes topográficas, esto porque no estaban destinadas a vivienda sino a equipamiento.

El programa de adquisición de suelo que actualmente tiene el Ivi, se considera que por la gran demanda de vivienda pudiera funcionar en un futuro para regular el costo del suelo, no obstante, algunos desarrolladores consideran que para abatir los costos del suelo es necesario coordinar-

${ }^{21}$ Durante la administración del gobernador Francisco Barrio Terrazas, 1992-1998. 
se y comprar tierra en conjunto; sin embargo, la competencia del mercado no ha permitido esto.

\begin{abstract}
Ahorita estamos abatiendo los rezagos, una vez que la demanda sea abatida [...] en los estratos económicos más bajos [...] probablemente el Instituto se convierta en aportante $[s i c]$ de reserva de tierra y regulador de suelo barato, en las dos ciudades más complicadas para adquisición de reserva aquí, Chihuahua y Juárez (Ivi, 2004).
\end{abstract}

Al respecto, los desarrolladores están de acuerdo en que sea el Ivi quien distribuya la tierra, ya que esto evitaría la especulación y los altos costos del suelo para vivienda nueva.

Por último se observa que la producción de vivienda rebasó la capacidad de dotación de infraestructura y vivienda. El crecimiento de las áreas nuevas, abiertas al desarrollo, obedece a la modificación en la generación de créditos que se hicieron en 2005 por parte del Infonavit, cuando ampliaron la cartera de los mismos para atender a la población de escasos recursos que no tenía acceso a la vivienda. Esto tomó desprevenido al gobierno e hizo que el proceso de urbanización se retrasara en términos de infraestructura, equipamientos y servicios.

\title{
6. Demanda de vivienda
}

Partiendo de que las altas tasas de crecimiento poblacional y de formación de hogares incrementa la demanda de vivienda (Dowall, 2000: 5), es posible decir que el mercado de vivienda de las ciudades del norte de México ha sido afectado por las altas tasas de crecimiento poblacional, ya que son centros que atraen una gran cantidad de migrantes.

Durante el periodo 1990-2000 la ciudad de Chihuahua tuvo una tasa de formación de hogares de 3.8\%, misma que se encuentra por arriba del promedio nacional, que es de $3.1 \%$, pero en comparación con la mayoría de las ciudades del norte de la República representa una tasa inferior (cuadro 4; Córdova et al., 2006).

En el año 2000, el déficit de vivienda en las principales ciudades de la frontera norte era el siguiente; Ciudad Juárez 4,980, Tijuana 4,282, Mexicali 2,640, Matamoros 2,139, Reynosa 1,724, Nuevo Laredo 645, Acuña 632, Nogales 335, Piedras Negras 433 y Chihuahua 2,419 (Córdova et al., 2006).

La demanda en la ciudad de Chihuahua se genera sobre todo en los barrios tradicionales y alrededor de éstos, que es donde se están construyendo los nuevos hogares (plano Iv; Córdova et al., 2006).

Un estudio de mercado elaborado por la empresa Urbis Internacionales, s.A. de C.v. (Urbisa, 2005) contratado por el Instituto de Vivienda 


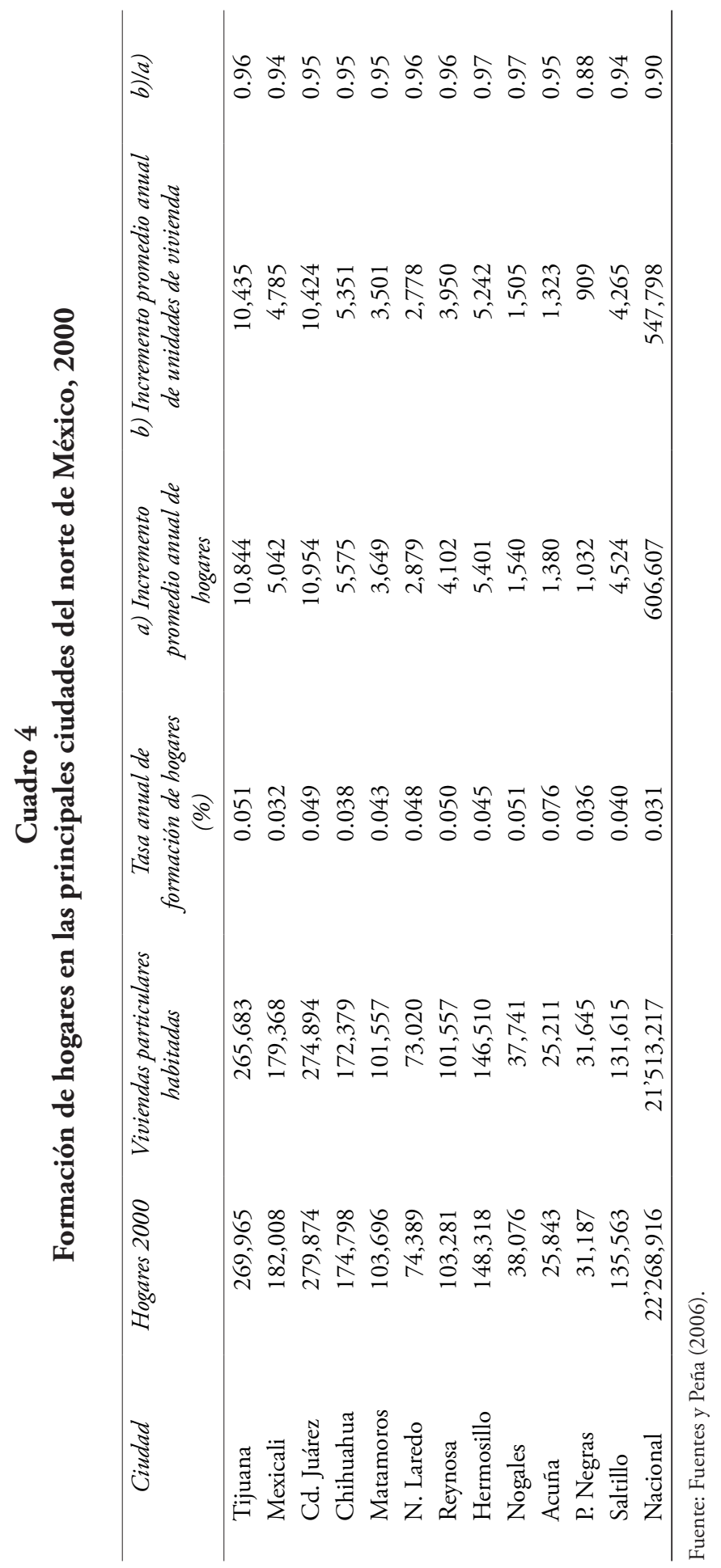




\section{Plano IV}

\section{Demanda de vivienda en la ciudad de Chihuahua}

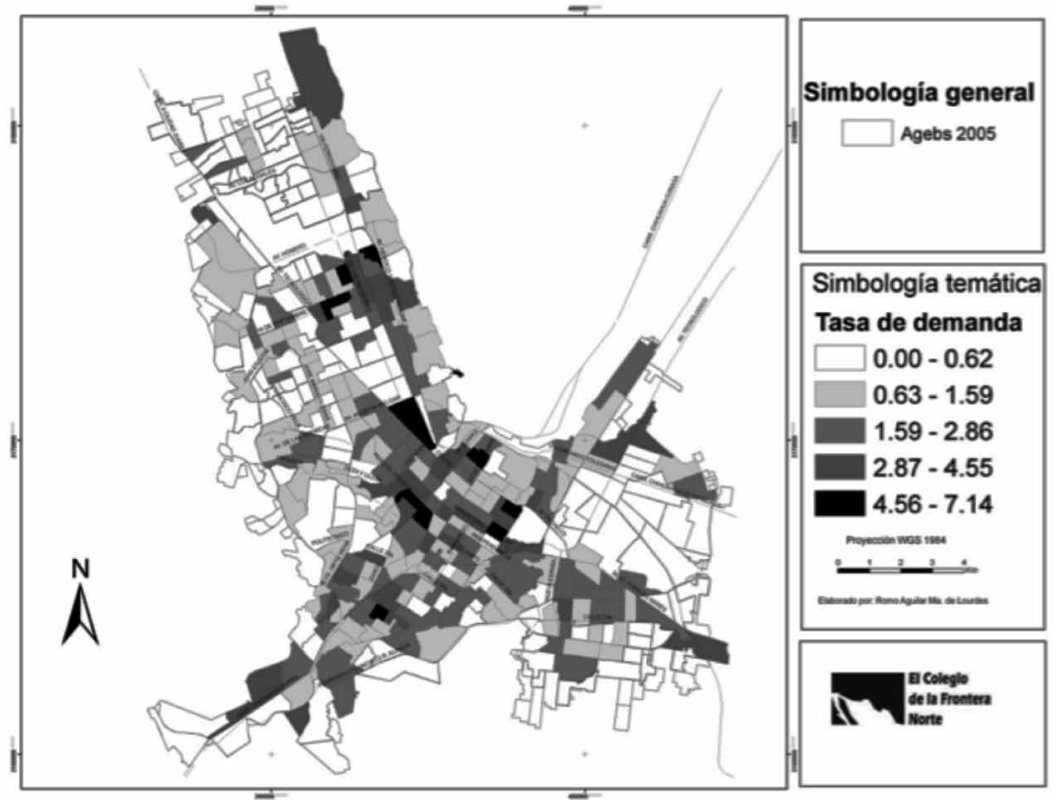

Fuente: Elaboración propia a partir de información del INEGI, 2009.

del estado señala para la ciudad de Chihuahua un déficit neto, de acuerdo con el censo de población y vivienda de 2000, de 2,419 unidades y establece que $18 \%$ de las viviendas no son propias, sino rentadas o prestadas; este dato es relativamente bajo si se compara con Ciudad Juárez (27 por ciento).

En términos generales, el déficit neto de vivienda en la ciudad de estudio es bajo, ya que representa apenas $1.4 \%$ del total del parque habitacional y el déficit de infraestructura y materiales se encuentran por debajo de $5 \%$ (en contraste con las zonas rurales, donde alcanza hasta 50 por ciento).

El mencionado estudio de Urbisa hace proyecciones de necesidades de vivienda basadas en las tasas de crecimiento, con lo que establece una demanda agregada de 7,332 viviendas nuevas a 2005 y 8,784 a 2010. Hay que considerar que la presión demográfica sólo tomaría $78 \%$ de la demanda de vivienda, y el resto se puede atribuir como producto de la inmigración. Estos datos contrastan enormemente con el Programa Institucional de Vivienda 2004-2010 del gobierno del estado, que establece una demanda de 48,614 unidades en este periodo. 
La demanda más importante la encontramos en el sector social de más bajos ingresos. De acuerdo con el censo del año 2000, 48\% de los habitantes del municipio percibían menos de tres salarios mínimos, por lo que el Fonhapo inició desde el ańo 2000 una política crediticia para este segmento de la población, considerando que en $44 \%$ de los hogares trabaja más de una persona. Si se suman los ingresos en el hogar y el incremento que han tenido los salarios de 2000 a 2005, las posibilidades de adquirir un crédito de vivienda son mayores.

Las personas con un nivel de ingreso socioeconómico bajo y quienes se encuentran en la economía informal tienen problemas para calificar en el acceso a créditos para adquisición de vivienda, por ello, desarrolladores como Urbi buscan financiar ellos mismos las viviendas solicitando requisitos mínimos. ${ }^{22}$

De acuerdo con la Cámara Nacional de la Industria de Desarrollo y Promoción de Vivienda (Canadevi), Chihuahua, se tiene una necesidad anual de 7,500 viviendas nuevas al ańo en la ciudad de Chihuahua, asimismo asegura que la producción anual de vivienda es de 8,000 unidades, y de éstas, 90\% es de interés social. Con esto se cubre la demanda anual, pero es necesario cubrir el déficit acumulado de los ańos anteriores que se estima entre 25,000 y 30,000 viviendas, de las cuales cerca de $70 \%$ son de interés social. ${ }^{23}$

De los problemas específicos que pudimos analizar en varias entrevistas con actores clave en relación con la demanda de vivienda, destaca el de la gestión que involucra la preparación de las instituciones gubernamentales ante el fenómeno, la mano de obra, la profesionalización de la actividad, la participación de los municipios, la transparencia, la posibilidad de ser incluyentes en los procesos y la responsabilidad social.

Cabe señalar que en el ámbito estatal existen dependencias de gobierno, como el Ivi, que consideran que tienen personal suficiente:

\footnotetext{
Al Instituto no le falta gente, y yo creo que tiene sus áreas muy bien definidas: una es la técnica, otra es la social y otra administrativa, estas tres tienen en su estructura muy bien qué es lo que van a hacer, entonces, de alguna manera práctica es una buena estructura con la que se opera (entrevista con el secretario del Ivi, Chihuahua, 14 de septiembre de 2006, ciudad de Chihuahua.
}

Entre 2003 y 2006 el Ivi participó en la edificación de 29,333 casas de las 81,333 viviendas construidas en el estado, mientras que en el ámbito municipal se observan problemas por falta de inspectores, como en el caso de la oficina de Desarrollo Urbano Municipal: "En cuestión de

\footnotetext{
${ }^{22}$ Gerente de Construcción Juárez, Urbi, entrevista, 26 de febrero de 2007, Ciudad Juárez, Chihuahua.

${ }^{23}$ Presidente de la Canadevi, entrevista 18 de septiembre de 2006.
} 
inspectores se requeriría un poco más, pero de hecho, de la administración pasada a ésta, sí tenemos más inspectores, nos han autorizado $50 \%$ más y en la administración urbana...” En cuestiones de profesionalización del personal, "la gente tiene mínimo estudios de licenciatura, pero un gran porcentaje tienen estudios de maestría, incluso de doctorado" (entrevista con la directora de Desarrollo Urbano Municipal, 20 septiembre de 2006, ciudad de Chihuahua).

En cuanto a la mano de obra, los desarrolladores consideran que tienen problemas con los contratistas principalmente por la falta de trabajadores, esto retrasa los tiempos de entrega de las viviendas.

Por su parte, en relación con la profesionalización se necesitan expertos en el área de urbanismo, ${ }^{24}$ particularmente se menciona la falta de apoyo de becas en las universidades para estudiar alguna especialización relativa al desarrollo de vivienda, así como promover más este tipo de carreras.

También se habla de una mayor participación del municipio y el sector industrial en la solución tanto del suelo como de la vivienda. Encontramos que los municipios sí deben participar en las acciones de vivienda, ya que ellos son los que autorizan el uso de suelo y tienen mayor información sobre las dinámicas urbanas. Sin embargo, se reconoce que el municipio por sí solo no puede atender la demanda. ${ }^{25}$

En general todos los organismos e instituciones entrevistadas cuentan con mecanismos de transparencia, a excepción del Colegio de Arquitectos que no maneja recursos financieros; las dependencias estatales y federales entraron al programa nacional de transparencia:

Definitivamente tenemos ya por ley un comité de transparencia, está en la Ley del Infonavit y ya se formaron, tenemos varios y diferentes comités, uno de ellos es el de medio ambiente que también tiene que ver con calidad de vida, se ocupa de la mejoría de los diseños y proyectos, y los está promoviendo, pero la Ley del Instituto fue renovada apenas el año pasado, y se publicó en esas fechas (entrevista al secretario de la delegación Infonavit, 14 de septiembre de 2006).

Asimismo, la Dirección de Desarrollo Urbano presenta el programa de certificación ISO 9000 que promueve la transparencia y la eficiencia. ${ }^{26}$ También las empresas manejan una filosofía de transparencia con sus proveedores. ${ }^{27}$

${ }^{24}$ Entrevistas con consultores en temas urbanos, 23 de agosto, 2 y 11 de septiembre de 2006, ciudad de Chihuahua.

${ }^{25}$ Dirección de Desarrollo Urbano, entrevista, 19 de septiembre de 2006.

${ }^{26}$ Dirección de Desarrollo Urbano, municipio de Chihuahua, entrevista, 20 de septiembre de 2006.

${ }^{27}$ Gerente de Ruba, entrevista, 6 de septiembre de 2006. 
En relación con la capacidad de incluir en su toma de decisiones a usuarios o población, los desarrolladores aplican preferentemente estudios de mercado realizados por empresas especializadas, sin embargo, no existe un estudio completo que incluya todas las viviendas con indicadores de preferencias por población o del proceso de apropiación de los espacios (Canadevi, 2006; Ruba, 2006). El Infonavit maneja una retroalimentación constante a través de entrevistas y encuestas con sus derechohabientes sobre los servicios que brinda. Acerca de la calidad de la vivienda, reconoce que no tienen un programa sobre calidad arquitectónica y las características del producto que ellos adquieren (Infonavit, 2006).

El municipio de Chihuahua, por su parte, conoce la satisfacción del cliente por medio de encuestas a la gente que asiste a las ventanillas de atención y a quienes hacen otros trámites en la Dirección de Desarrollo Urbano, e incluso han aplicado encuestas telefónicas. Por otro lado, el sector académico considera que las instituciones de vivienda pública y privada no son incluyentes en el sentido de que no integran las demandas de ciertos grupos de la población, como estudiantes y profesionistas: "Seas estudiante, recién egresado, anciano, te toca comprar una casa como todos, no hay departamentos, no hay esquemas como en otras ciudades" (profesor del Instituto de Arquitectura y Diseńo de la UACH, entrevista, 26 de agosto de 2006).

La responsabilidad en términos de desarrollo social es muy precaria. Los desarrolladores asumen su responsabilidad social y consideran que aún se tiene que avanzar en muchos aspectos con respecto al tema social (Canadevi, 2006). Uno de los problemas que se perciben es que se está atendiendo más la cobertura del déficit y necesidad de vivienda que a las personas. Sólo en la empresa Urbi encontramos conceptos novedosos, como el de comunidad que incluye un proceso de acompañamiento social con la población de los fraccionamientos, ayudándolos a crear un fideicomiso, a organizarse y desarrollar estrategias de convivencia.

\section{Conclusiones}

Sin duda el tema de vivienda nueva es uno de los factores más importantes de ocupación del espacio urbano en la ciudad de Chihuahua. Dicha ocupación sigue invariablemente los patrones de las ciudades de las llamadas economías emergentes al acompañar el desarrollo industrial. Los fraccionamientos con vivienda nueva se ubican principalmente hacia el norte, donde se localizan los parques industriales más importantes.

Este fenómeno ha tenido efecto en la estructura urbana al fortalecer los nuevos subcentros al norte y sureste, pues se ha debido ampliar la infraestructura vial, hidráulica y eléctrica, así como el equipamiento ur- 
bano que incluye escuelas, parques, centros de salud, seguridad y protección civil, entre otros.

En cuanto a calidad de la vivienda, el municipio de Chihuahua tiene menos porcentaje de vivienda con materiales precarios que otros municipios norteños, y también está por debajo del porcentaje nacional. Esto se explica porque dentro de la mancha urbana, los fraccionamientos con vivienda nueva incrementan considerablemente los índices de calidad de vivienda manejados por los gobiernos, no obstante hay que señalar que en el resto de la ciudad este aspecto no se distribuye de manera homógenea.

Sobre este tema los profesionistas y académicos señalan que la calidad se relaciona directamente con los bajos ingresos y que los desarrolladores no tienen interés en un diseño con mayor calidad en términos de habitabilidad de vivienda porque no es redituable. Por su parte, los desarrolladores lo asocian con los costos de urbanización que, según señalan, los obligan a ofrecer productos de menor calidad, pero en general consideran que tienen buena calidad de vivienda, y que el tamaño tiene que ver con los límites del crédito que se otorga a los derechohabientes y con el incremento en el costo de materiales que no es proporcional con el aumento del salario mínimo.

Si bien la calidad se maneja en relación con los materiales de construcción, se dejan de lado otros aspectos que podrían incluirse en este rubro, como espacio suficiente para evitar el hacinamiento con su consabido daño psicológico y emocional, accesibilidad física, seguridad, disponibilidad de servicios y medio ambiente saludable. Esto último tiene que ver con el efecto ambiental que ocasiona la construcción de vivienda nueva donde predomina la construcción con block de concreto, material que no es adecuado para las condiciones climáticas de la región, lo que contradice los planes y programas ambientales.

En cuanto a la oferta, la tasa de formación de hogares de la ciudad de Chihuahua es de $3.8 \%$, por arriba de la nacional (3.1\%), lo que indica una demanda importante, sin embargo, en los últimos años el problema se ha enfocado mayormente en un sector de la población con ingresos bajos que representa la mitad de la población, y que por múltiples razones no había tenido la oportunidad de adquirir una vivienda nueva.

En especial la demanda de vivienda se localiza en el sector central de la ciudad y en el nororiente por su cercanía con el comercio, los servicios y las fuentes de empleo, mientras que en la periferia urbana hay una oferta subutilizada cuyo aprovechamietno depende en gran medida de la formación de hogares con intenciones de adquirir vivienda nueva y de que existan ofertas atractivas.

Es evidente la necesidad de ofertar otro tipo de programas de vivienda, como la de mejoramiento, aunque hasta ahora para el Ivi y el Infona- 
vit no sean importantes y buscan, en todo caso, que sea el gobierno municipal quien se encarge de los programas de mejoramiento y ampliación de vivienda. La responsabilidad de las autoridades en la regulación y en encabezar los programas sociales es necesaria, por ello se debe seguir analizando el tema de las concurrencias en la materia.

En este sentido, hay coincidencia entre los sectores entrevistados y los resultados de la encuesta aplicada en que el gobierno ha cedido espacio y responsabilidades en cuanto a definir la política de vivienda y que esto ha sido un equívoco, debe ser el gobierno quien concrete y encabece dicha política y no los desarrolladores. Si bien el gobierno municipal no tiene los grandes programas de desarrollo de vivienda, conserva el derecho de autorizar el uso de suelo y es el responsable de su planificación y dotación de gran parte de la infraestructura y los servicios públicos.

Es importante, entonces, que el gobierno municipal asuma un papel activo para definir e implementar sus propios programas dirigidos a la vivienda. Las políticas de descentralización le otorgan atribuciones y responsabilidades para llevar a cabo esto, pero los principales recursos (no sólo económicos, sino operativos, técnicos, humanos, etc.) los concentran dependencias del gobierno federal. Una parte del presupuesto o fondos especiales manejados por estas dependencias se deberían destinar a los municipios y metrópolis que presentan serios problemas derivados de la ocupación del suelo.

Los desarrolladores afirman que la vivienda es un negocio, sin embargo están conscientes que las condiciones de los desarrollos que construyen pueden mejorar. No obstante, demandan que las regulaciones que actualmente tienen sobre la infraestructura se disminuyan, asimismo, observaron la necesidad de una mejor coordinación entre ellos y las instancias gubernamentales.

Se observa que el Estado por sí solo no es capaz de garantizar una vivienda digna. En el contexto actual, tiene que haber una conjunción de esfuerzos entre todos los actores que viven la ciudad. Los desarrolladores privados deben asumir un papel responsable con la comunidad y el medio ambiente local, al ofrecer vivienda digna que influya en el desarrollo social y que corresponda con la menor demanda de materiales y energía de la región. Es importante la participación de todos los actores sociales: iniciativa privada, academia, sociedad civil y gobierno en la construcción de la política de vivienda, pero debe ser el actor gubernamental quien encabece y concrete dicha política y en un ejercicio de retroalimentación y gobernabilidad democrática, posterior a su aplicación, ésta deberá ser evaluada de forma integral por todos los sectores sociales para reformarla y mejorarla. 


\section{Bibliografía}

Álvarez, Luis (1999), "Nuevo modo de regulación y producción de la vivienda", Ciudades, 44, Red Nacional de Investigación Urbana, Benemérita Universidad Autónoma de Puebla, Puebla, pp. 48-52.

Bettin, Gianfranco (1982), Los sociólogos de la ciudad, Gustavo Gili, Barcelona.

Canadevi (2006), entrevista al presidente de Canadevi, 18 de septiembre de 2006, en Gustavo Córdova, Lourdes Romo, César Fuentes y Alejandro Brugués, "Estudio del espacio urbano en Chihuahua, Chihuahua: una evaluación de la vivienda y los barrios tradicionales, del equipamiento y la factibilidad de densificación urbana: evaluación de vivienda", proyecto financiado por Implan, Chihuahua, El Colegio de la Frontera Norte-Implan, reporte técnico, mimeo.

Capiu (Capacitación e Investigación Urbana) (1999), "El derecho a una vivienda adecuada", Ciudades, 44, ańo 11, Red Nacional de Investigación Urbana, Benemérita Universidad Autónoma de Puebla, Puebla, pp. 3-8.

Córdova, Gustavo, Lourdes Romo, César Fuentes y Alejandro Brugués, (2006), "Estudio del espacio urbano en Chihuahua, Chihuahua: una evaluación de la vivienda y los barrios tradicionales, del equipamiento y la factibilidad de densificación urbana: evaluación de vivienda", proyecto financiado por Implan, Chihuahua, El Colegio de la Frontera Norte-Implan, reporte técnico, mimeo.

Coulomb, René (1989), "Política de vivienda y necesidades habitacionales”, Ciudades, 4, año 1, Red Nacional de Investigación Urbana, Benemérita Universidad Autónoma de Puebla, Puebla, pp. 33-38.

Dowall, David (2000), "Urban land management issues and opportunities in developing countries", Lincoln Institute of Land Policy, Cambridge, MA.

Duhau, Emilio (1997), "Pobreza, ciudadanía y política social en América Latina”, Ciudades, 36, año 9, Red Nacional de Investigación Urbana, Benemérita Universidad Autónoma de Puebla, Puebla, pp. 3-13. 
Fuentes, César y Sergio Peña (2006), "La política de vivienda en la frontera norte de México", en Gerardo Ordóńez y Marcos Reyes (coords.), Los retos de la politica social en la frontera norte de México, El Colegio de la Frontera-Plaza y Valdés, pp. 213-243.

García de León, Armando (2006), "Cuantificación de las características físicas de la vivienda urbana en México", Boletín de los Sistemas Nacionales Estadistico y de Información Geográfica, 2 (2), INEGI, Aguascalientes, pp. 119-140.

Garza, Gustavo (2001), "Globalización económica y planeación estratégica del desarrollo urbano de Tamaulipas”, en Rolando García, Alfonso Iracheta y Emilio Duhau (comps.), Planeación y gestión urbana y metropolitana en México, El Colegio de la Frontera Norte-El Colegio Mexiquense, México, pp. 91-126.

Garza, Gustavo, Pierre Filion y Gary Sands (2003), Politicas urbanas en grandes metrópolis, El Colegio de México, México.

Godard, Francis (1998), "Algunos aspectos en juego en el futuro de nuestras ciudades", Ciudades, 37, año 10, Red Nacional de Investigación Urbana, Benemérita Universidad Autónoma de Puebla, Puebla, pp. 36-43.

Ímaz, Carlos y Beatriz García (1997), "Desregulación y política de vivienda en México", Ciudades, 36, año 9, Red Nacional de Investigación Urbana, Benemérita Universidad Autónoma de Puebla, Puebla, pp. 31-36.

INEGI (Instituto Nacional de Estadística, Geografía e Informática) y Secretaría de Programación y Presupuesto (spP) (1986), X Censo General de Población y Vivienda 1980, INEGI, México.

INEGI (Instituto Nacional de Estadística, Geografía e Informática) (1992), XI Censo General de Población y Vivienda 1990, Inegi, Aguascalientes.

INEGI (Instituto Nacional de Estadística, Geografía e Informática) (1997), Conteo de Población y Vivienda 1995, Base de datos de la encuesta y tabulados complementarios, INEGI, México, disco compacto. 
INEGI (Instituto Nacional de Estadística, Geografía e Informática) (2002), XII Censo General de Población y Vivienda 2000, InEgI, Aguascalientes.

INEGI (Instituto Nacional de Estadística, Geografía e Informática) (2009), II Conteo de Población y Vivienda 2005, INegi, México, disco compacto.

Infonavit (2006), entrevista al secretario de Infonavit, 14 de septiembre de 2006, en Gustavo Córdova, Lourdes Romo, César Fuentes y Alejandro Brugués, "Estudio del espacio urbano en Chihuahua, Chihuahua: una evaluación de la vivienda y los barrios tradicionales, del equipamiento y la factibilidad de densificación urbana: evaluación de vivienda", proyecto financiado por Implan, Chihuahua, El Colegio de la Frontera Norte-Implan, reporte técnico, mimeo.

IVI (Instituto de la Vivienda del Estado) (2004), Programa institucional de vivienda 2004-2010, Gobierno del Estado de Chihuahua, Chihuahua.

Lezama, José Luis (1993), Teoría social, espacio y ciudad, El Colegio de México, México.

Moreno, Adrián (1989), "Crisis del desarrollo urbano en San Luis Potosî”, Ciudades, 3, año 1, Red Nacional de Investigación Urbana, Benemérita Universidad Autónoma de Puebla, Puebla, pp. 38-42.

Morillo, Juan (2004), "La protección pública y el papel de las administraciones en el acceso a una vivienda digna. Las experiencias de Andalucía", Boletín del Instituto de la Vivienda, 19 (50), Universidad de Chile, Santiago, pp. 106-131.

Pradilla, Emilio (1982), Ensayos sobre la problemática de la vivienda en América Latina, Universidad Autónoma Metropolitana, Xochimilco, México.

Pozas, María de los Ángeles (1989), "Burocracia y vivienda en Monterrey”, Ciudades, 3, año 1, Red Nacional de Investigación Urbana, Benemérita Universidad Autónoma de Puebla, Puebla, pp. 43-50. 
Puebla, Claudia (1999), "Del Estado interventor al Estado facilitador", en Ciudades, núm. 44, octubre-diciembre, RNiv, Puebla, México.

Quezada, Manuel (2007), “Sector vivienda, acciones para el 2007”, Concreto, 17, cmic, México, pp. 12-13.

Ruba (2006), entrevista al gerente de Ruba, s.A., 6 de septiembre de 2006, en Gustavo Córdova, Lourdes Romo, César Fuentes y Alejandro Brugués, "Estudio del espacio urbano en Chihuahua, Chihuahua: una evaluación de la vivienda y los barrios tradicionales, del equipamiento y la factibilidad de densificación urbana: evaluación de vivienda", proyecto financiado por Implan, Chihuahua, El Colegio de la Frontera Norte-Implan, reporte técnico, mimeo.

Salcedo, Roberto (2000), "Problemática social de la vivienda en México", Federalismo y Desarrollo, 13, Banobras, México, pp. 7-18.

un-Habitat (2003), Handbook on Best Practices, Security of Tenure and Access to Land, onu, Nairobi.

Unikel, Luis, Crescencio Ruiz y Gustavo Garza (1976), El desarrollo urbano de México. Diagnóstico e implicaciones futuras, El Colegio de México, México.

Urbisa Internacional (2005), "Estudio de oferta y demanda de vivienda en el estado de Chihuahua, en las ciudades de Chihuahua, Juárez, Parral, Delicias, Cuauhtémoc, para el Instituto de Vivienda del Estado", Urbisa, Chihuahua, mimeo.

Villavicencio, Judith (1997), "Vivienda para los más pobres: ¿el olvido?”, Ciudades 36, año 9, México, pp. 46-51.

Recibido: 18 de noviembre de 2009. Reenviado: 29 de julio de 2010. Aceptado: 14 de marzo de 2011.

María de Lourdes Romo-Aguilar. Es doctora en ciencias sociales con especialización en relaciones de poder y cultura política por la Universidad Autónoma Metropolitana, Xochimilco; es maestra en administración integral del ambiente por el Colegio de la Frontera, y licenciada en geografía por la Universidad de Guadalajara. Sus líneas de investigación son: 
vulnerabilidad y riesgos, ordenamiento ecológico, administración de recursos naturales con herramientas como sistemas de información geográfica y percepción remota. Es investigadora del Sistema Nacional de Investigadores (SNI) nivel I. Ha participado en 13 proyectos y ha sido responsable de seis proyectos de investigación. Es dictaminadora de varias revistas y actualmente titular de la Comisión Evaluadora del Departamento de Estudios Urbanos y de Medio Ambiente de El Colegio de la Frontera Norte. Ha publicado 35 artículos y capítulos de libro. Sus publicaciones más recientes son: en coautoría, "Proceso de gestión en el ordenamiento ecológico y territorial del municipio de Juárez, Chihuahua", en Gerardo Bocco et al., Nuevas formas de gestión ambiental: agua y ordenamiento ecológico territorial, El Colegio de la Frontera Norte, Tijuana, pp. 133-165 (2009); "Vulnerability to environmental hazards in the Ciudad Juárez (Mexico)-El Paso (USA) metropolis: A model for spatial risk assessment in transnational context", Applied Geography Journal, 29 (3), Elsevier, Grineski, pp. 448-461 (2008); "No Safe Place: Environmental Hazards \& Injustice along Mexico's Northern Border”, Social Forces Journal, 88 (5), Elsevier, pp. 2241-2266 (2009).

Gustavo Córdova-Bojorquez. Es doctor en ciencias sociales por la Universidad Autónoma Metropolitana, Xochimilco, con especialidad en relaciones de poder y cultura política. Realizó sus estudios de maestría en El Colegio de la Frontera Norte en administración integral del ambiente. Es miembro del Sistema Nacional de Investigadores, nivel I. Sus líneas temáticas de investigación son: gestión ambiental, gobiernos locales y gestión binacional en materia ambiental y políticas públicas y procesos sociales. Es autor y coautor de 24 artículos arbitrados en revistas especializadas nacionales e internacionales. Autor del libro La gestión ambiental en Ciudad Juárez, El Colegio de la Frontera-Miguel Ángel Porrúa, Tijuana (en prensa).

César M. Fuentes-Flores. Es maestro en desarrollo regional por El Colegio de la Frontera Norte, y doctor en planeación urbana y regional por la Universidad del Sur de California. Sus temas de investigación son: planeación urbana (movilidad intraurbana, marcados de suelo, vivienda, etc.) y planeación transfronteriza. Pertenece al Sistema Nacional de Investigadores, nivel III. Ha publicado 20 artículos en revistas especializadas nacionales e internacionales y 15 capítulos en libros. Es autor del libro Inversión en infraestructura pública y productividad regional de la industria manufacturera en México, El Colegio de la Frontera-Plaza y Valdés (2007); coordinador de Planeación binacional y cooperación transfronteriza en la frontera México-Estados Unidos, El Colegio de la Frontera-IUACJ, Tijuana (2005); coeditor de Cities and Citizenship at the El Paso del Norte Region, 
Palgrave Mcmillian, Nueva York (2009). Ha participado en más de 40 conferencias en México, Estados Unidos y Canadá.

Alejandro Brugués-Rodríguez. Es maestro en economía aplicada por El Colegio de la Frontera Norte, y doctor en ciencias económicas por la Universidad Autónoma de Baja California. Sus temas de investigación son economía urbana y regional, y desarrollo económico. Pertenece al Sistema Nacional de Investigadores, en la categoría de candidato. Entre sus publicaciones destacan: en coautoría, "Movilidad cotidiana de la población en cuatro ciudades sinaloenses: estructura urbana y características de los desplazamientos por trabajo y estudio", en Juan Carlos Leyva López et al., Herramientas operativas para el análisis multicriterio. Universidad de Occidente, Universidad de Occidente-Plaza y Valdés, México, pp. 507-552 (2009); en coautoría, "El sistema grit para la estimación de matrices insumo-producto regional”, en Noe Arón Fuentes Flores, 25 años de investigación sobre la frontera norte de México, El Colegio de la Frontera Norte, Tijuana, pp. 379-400 (2008); en coautoría, "La simulación del crecimiento urbano en la ciudad de Chihuahua", en Naú Silverio Niño Gutiérrez, Estudios territoriales, Geotech, La Habana, pp. 95-120 (2008); "Relaciones económicas y niveles de bienestar en Ciudad Juárez: un enfoque de género", en Luis Cervera, Diagnóstico geosocioeconómico de Ciudad Juárez y su sociedad, El Colegio de la Frontera Norte-Inmujeres, México, pp. 66-113 (2006). 